\title{
Plasma Insulin and Free Fatty Acids in Young People with Postprandial Glycosuria: Plasma Insulin Response in the Cases with Borderline Glucose Tolerance Test
}

\author{
Yoshio Goto, Shin-Ichiro Sato, Sei-ichi Ohira, and Yoshisuke Maruhama \\ Third Department of Internal Medicine, Hirosaki University School of Medicine, Hirosaki, Japan, \\ and Third Department of Internal Medicine, Tohoku University School of Medicine, Sendai, Japan
}

Received: December 16,1972 , accepted: April 2, 1973

\begin{abstract}
Summary. Plasma immunoreactive insulin and free fatty acid (F.F.A.) responses to an oral glucose load were observed in young students with glycosuria and with glucose intolerance of a slight degree. - The groups with a diabetic or a borderline glucose tolerance test (G.T.T.) had a delayed and protracted plasma insulin and F.F.A. response. Both responses were significantly greater than in the control group. The result indicates that a sluggish but high rise and a delayed fall of plasma insulin during the glucose load is characteristic of chemical diabetics and this tendency is seen in the cases with a borderline G.T.T.

- The subjects with oxyhyperglycemic G.T.T. also had
\end{abstract}

an initial delay in the insulin response and the peak was distinctly higher than in the control, but the fall was sharp. This suggests that oxyhyperglycemia is one of the preceding states of diabetes. - The subjects with renal glycosuria, in the definition of Lawrence, had a highnormal G.T.T., but their insulin and F.F.A. responses showed no difference from those of the normal.

Key words: Glucose tolerance test, chemical diabetes, plasma insulin response, plasma free acids, oxyhypergly cemia, renal glycosuria.
Diabetes mellitus is a disease of a progressive nature but of variable course. Some cases have a rapid course to the complicated or terminal stage while others remain stable and asymptomatic throughout their lives, in spite of the similarity of their environmental conditions. What is a limiting factor(s) of the course of this disease? Are there any difference in the etiology or in the genetic factors? What changes do occur when the diabetic state starts? These questions have prompted us to study the pathophysiology of the stage around the onset of diabetes.

Although there has been a steadily growing accumulation of findings on the early stage of diabetes during the past decade, our knowledge is still incomplete and some disagreements are seen in, for instance, the plasma insulin response $(1-6)$.

The present study was designed to ascertain the plasma insulin and the plasma free fatty acid (F.F.A.) response to a glucose load in young people with postprandial glycosuria and subminimal glucose intolerance.

\section{Materials and Methods}

The screening test was made on 9544 students, by using Tes-Tape to detect glucose in urine collected one to two hours after lunch. The subjects consisted of 1708 senior high school boys (age 15-18), 1396 junior and senior high school girls (age 13-18) and 6440 University students (age 19-29,5228 boys and 1212 girls). The test was positive in 253 cases and the $100 \mathrm{~g}$ oral glucose tolerance test was performed on 210 of these and on 34 volunteers, without a family history of diabetes and with negative screening test, as a control.
The oral G.T.T. was performed in the early morning after an overnight fast. The blood specimens were collected by antecubital venepuncture using heparinized syringes, prior to and $30,60,90$ and $120 \mathrm{~min}$ after glucose ingestion. Blood glucose was estimated by the glucose-oxidase method (Glucostat, Worthington Biochemical Co.); plasma immunoreactive insulin was determined by the double antibody system of Morgan and Lazarow [7] and plasma F.F.A. was measured by the method of Itaya and Ui [8].

The glueose tolerance test was interpreted by the following five criteria. Normal: peak below $140 \mathrm{mg} / \mathrm{dl}$,

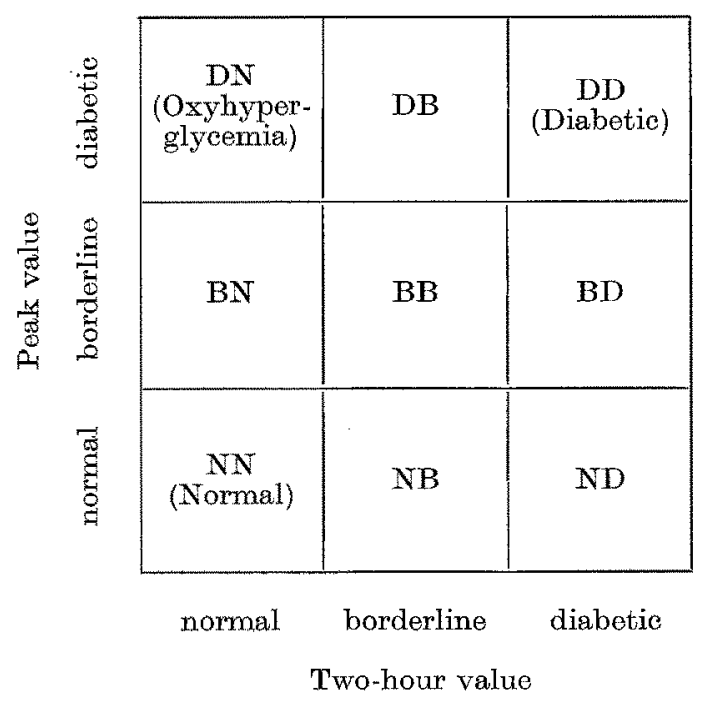

Fig. 1. Classification of glucose tolerance curves according to combination of the peak value and the two-hour value 
$120 \mathrm{~min}$ below $110 \mathrm{mg} / \mathrm{dl}$ and no glycosuria. Diabetic : peak above $160 \mathrm{mg} / \mathrm{dl}$ and $120 \mathrm{~min}$ above $140 \mathrm{mg} / \mathrm{dl}$; Oxyhyperglycemia : peak above $160 \mathrm{mg} / \mathrm{dl}$ and $120 \mathrm{~min}$ below $110 \mathrm{mg} / \mathrm{dl}$; Borderline : test not satisfying above combinations. The definition of renal glycosuria was that of Lawrence [9], i.e. normal G.T.T. with positive urine sugar.

In previous papers $[10,11]$, we classified G.T.T.s by the combination of the peak and the two hour value into nine types, as shown in Fig. 1. If the peak is in the diabetic zone and the two hour value is in the borderline zone, the G.T.T. is expressed as DB. The diabetic diabetic. Cases ten percent or more overweight, from the Japanese standard body weight, or with abnormal physical findings suggesting endocrine or liver diseases were excluded from these groupings. Lawrence [9] used the capillary blood sugar when he classified renal glycosuria. In this report, however, the venous blood was used for estimation of insulin and F.F.A. and the classification of the G.T.T. was also made using venous blood glucose values. The capillary-venous blood sugar difference during G.T.T. has been described elsewhere $[13,14]$.

Table 1. Results of urine sugar screening and $100 \mathrm{~g}$ G.T.T. in 9544 students

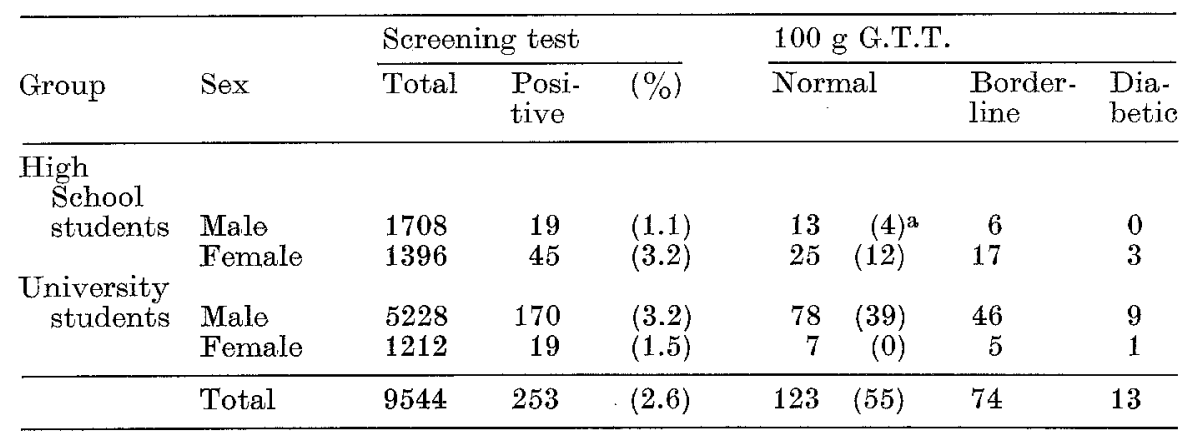

a The figures in parenthesis show the cases with positive urine sugar during G.T.T.

Table 2. Blood glucose, plasma immunoreactive insulin and plasma F.F.A. during 100 g G.T.T. in young people

\begin{tabular}{|c|c|c|c|c|c|c|c|c|}
\hline Substance & Group & (No) & Fast & & $30 \min$ & $60 \mathrm{~min}$ & $90 \mathrm{~min}$ & $120 \mathrm{~min}$ \\
\hline $\begin{array}{l}\text { Blood } \\
\text { Glucose } \\
\text { (mg/dl) }\end{array}$ & $\begin{array}{l}\text { Normal } \\
\text { Renal glycosuric } \\
\text { Oxyhyperglycemic } \\
\text { Borderline } \\
\text { Diabetic }\end{array}$ & $\begin{array}{l}(34) \\
(24) \\
(14) \\
(30) \\
(11)\end{array}$ & $\begin{array}{r}85.1 \pm \\
84.0 \pm \\
92.9 \pm \\
87.7 \pm \\
105.0 \pm\end{array}$ & $\begin{array}{l}1.4 \\
1.8 \\
2.5^{b} \\
1.3 \\
6.6^{b}\end{array}$ & $\begin{array}{l}108.8 \pm 3.4 \\
126.5 \pm 2.7 \mathrm{~b} \\
179.5 \pm 10.8^{\mathrm{b}} \\
142.0 \pm 4.0^{\mathrm{b}} \\
167.5 \pm 8.1^{\mathrm{b}}\end{array}$ & $\begin{array}{l}101.5 \pm 2.9 \\
113.0 \pm 4.4^{\mathrm{a}} \\
156.0 \pm 11.3^{\mathrm{b}} \\
145.5 \pm 3.6^{\mathrm{b}} \\
195.4 \pm 8.5^{\mathrm{b}}\end{array}$ & $\begin{array}{c}90.5 \pm 2.8 \\
95.4 \pm 3.1 \\
111.3 \pm 6.0^{\mathrm{b}} \\
134.1 \pm 3.4^{\mathrm{b}} \\
186.0 \pm 12.5^{\mathrm{b}}\end{array}$ & $\begin{aligned} 84.7 \pm 1.6 \\
94.5 \pm 2.4^{\mathrm{b}} \\
89.9 \pm 4.6^{2} \\
120.4 \pm 1.2^{\mathrm{b}} \\
169.0 \pm 7.8^{\mathrm{b}}\end{aligned}$ \\
\hline $\begin{array}{l}\text { Plasma } \\
\text { Insulin } \\
(\mu \mathrm{u} / \mathrm{ml})\end{array}$ & $\begin{array}{l}\text { Normal } \\
\text { Renal glycosuric } \\
\text { Oxyhyperglycemic } \\
\text { Borderline } \\
\text { Diabetic }\end{array}$ & $\begin{array}{l}(34) \\
(24) \\
(14) \\
(30) \\
(11)\end{array}$ & $\begin{array}{l}22.3 \pm \\
15.7 \pm \\
30.3 \pm \\
15.7 \pm \\
13.7 \pm\end{array}$ & $\begin{array}{l}2.9 \\
2.1 \\
8.8 \\
2.1 \\
2.4\end{array}$ & $\begin{array}{l}88.9 \pm 9.2 \\
91.5 \pm 10.9 \\
76.7 \pm 17.9 \\
90.7 \pm 15.4 \\
50.5 \pm 6.1^{\mathrm{a}} \\
\end{array}$ & $\begin{array}{c}84.7 \pm 9.2 \\
90.3 \pm 9.5 \\
143.0 \pm 25.3^{\mathrm{a}} \\
103.8 \pm 18.6 \\
66.4 \pm 7.2 \\
\end{array}$ & $\begin{array}{c}78.0 \pm 7.5 \\
90.3 \pm 13.5 \\
98.8 \pm 12.9 \\
102.9 \pm 11.7 \\
130.9 \pm 28.4^{b}\end{array}$ & $\begin{array}{r}72.7 \pm 7.2 \\
71.8 \pm 7.3 \\
76.1 \pm 17.5 \\
107.5 \pm 12.0^{\mathrm{a}} \\
121.4 \pm 25.1^{\mathrm{b}} \\
\end{array}$ \\
\hline $\begin{array}{l}\text { Plasma } \\
\text { Free } \\
\text { Fatty } \\
\text { Acids } \\
(\mu \text { Eq } / L)\end{array}$ & $\begin{array}{l}\text { Normal } \\
\text { Renal glycosuric } \\
\text { Oxyhyperglycemic } \\
\text { Borderline } \\
\text { Diabetic }\end{array}$ & $\begin{array}{l}(34) \\
(24) \\
(14) \\
(30) \\
(11)\end{array}$ & $\begin{array}{l}568 \pm \\
698 \pm \\
720 \pm \\
835 \pm \\
996 \pm\end{array}$ & $\begin{array}{l}74 \\
78^{\mathrm{b}} \\
14^{\mathrm{b}}\end{array}$ & $\begin{array}{l}354 \pm 33 \\
381 \pm 39 \\
370 \pm 40 \\
426 \pm 30 \\
607 \pm 70^{\mathrm{b}}\end{array}$ & $\begin{array}{l}261 \pm 18 \\
292 \pm 24 \\
258 \pm 29 \\
355 \pm 30^{b} \\
495 \pm 81^{b}\end{array}$ & $\begin{array}{ll}264 & \pm 22 \\
280 & \pm 28 \\
201 & \pm 19 \\
276 & \pm 23 \\
406 & \pm 39 b\end{array}$ & $\begin{array}{ll}237 & \pm 16 \\
280 & \pm 34 \\
200 & \pm 18 \\
247 & \pm 20 \\
299 & \pm 37\end{array}$ \\
\hline
\end{tabular}

$\mathrm{M} \pm \mathrm{SE}$, a $P<0.05$, b $P<0.01$ (against normal)

curve is expressed as DD and the normal curve as NN. The borderline G.T.T.s, therefore, are classified into seven types, i.e. $\mathrm{DB}, \mathrm{DN}, \mathrm{BD}, \mathrm{BB}, \mathrm{BN}, \mathrm{ND}$ and $\mathrm{NB}$. The curve of DN is "oxyhyperglycemia". The types of $\mathrm{DB}, \mathrm{BD}$ and $\mathrm{BB}$ sometimes develop to diabetic in a relatively short period $[10,12]$ and the subjects of the borderline group selected for the present study had these types of G.T.T.

In this report, limited numbers of cases with a typical curve were selected for each group, i.e. 24 renal glycosuric, 14 oxyhyperglycemic, 30 borderline and 11

\section{Results}

\section{Glucose Tolerance Test}

The screening test was positive in 253 of the 9544 students; in 189 of the 6936 male students $(2.7 \%)$ and in 64 of the 2608 female students (2.4\%) (Table 1).

The oral glucose tolerance test, performed on 210 students, yielded 13 diabetic, 74 borderline and 123 normal types. The urine, tested during the G.T.T., was positive in 134 cases $(63.8 \%)$ and this figure shows 
that urine sugar exoretion in juvenile subjects is not consistent. In some cases, perhaps, the urine sugar becomes positive only under stress conditions such as mental and physical tension. A diabetic curve was obtained in 9 of the 151 male students $(5.9 \%)$ and in 4 of the 59 female students $(6.7 \%)$.

\section{Blood Glucose Curve}

The mean blood glucose values during the $100 \mathrm{~g}$ G.T.T., grouped by the diagnostic criteria, are shown in Table 2. The mean fasting blood glucose of the oxyhyperglycemic group and also of the diabetic group was significantly higher than that of the normal group. The mean $30 \mathrm{~min}$ values were significantly higher than the normal in four groups and was also significantly higher in the oxyhyperglycemic, borderline and diabetic groups compard with the renal glycosuric group $(P<0.01)$. The same relationship was also obtained with the mean $60 \mathrm{~min}$ blood glucose value. The mean 90 min value was higher in the oxyhyperglycemic, the borderline and the diabetic than in the normal group. The mean 120 min value was higher in the borderline

\section{Plasma Free Fatty Acids}

The changes in plasma F.F.A. during the G.T.T. are shown in Table 2. The mean fasting plasma F.F.A. was significantly higher in the diabetic and the borderline groups than in the normal and slightly higher in the renal glycosuric and the oxyhyperglycemic groups, although the difference was not significant. The mean values after glucose ingestion were also significantly higher in the diabetic group and at the $60 \mathrm{~min}$ period in the borderline group.

The decrease of plasma F.F.A. in percent is summarized in Table 3. The decrease was most prominent in the oxyhyperglycemic group throughout the period. The fall at $120 \mathrm{~min}$ was significantly greater in the dia. betic and the borderline groups than in the normal.

\section{Discussion}

In the natural history of diabetes mellitus, it may be that the derangement in carbohydrate metabolism occurs and develops insidiously at its initial stage and

Table 3. Changes in plasma F.F.A. during $100 \mathrm{~g}$ G.T.T. expressed in percent to the fosting level

\begin{tabular}{|c|c|c|c|c|c|}
\hline Group & (No) & $30 \mathrm{~min}$ & $60 \mathrm{~min}$ & $90 \mathrm{~min}$ & $120 \mathrm{~min}$ \\
\hline Normal & (34) & $63.0 \div 3.5$ & $50.0 \pm 3.1$ & $49.2 \pm 3.4$ & $46.8 \pm 3.6$ \\
\hline Renal glycosuric & (24) & $57.3 \pm 4.4$ & $47.5 \pm 4.5$ & $43.4 \pm 3.8$ & $51.2 \pm 8.5$ \\
\hline Oxyhyperglycemic & (14) & $51.9 \pm 3.1$ & $37.0 \pm 3.4^{\mathrm{a}}$ & $30.6 \pm 2.9^{b}$ & $30.8 \pm 4.0^{\mathrm{a}}$ \\
\hline Borderline & (30) & $55.3 \pm 3.7$ & $46.5 \pm 3.8$ & $37.1 \pm 3.4^{\mathrm{a}}$ & $35.3 \pm 3.4^{\mathrm{a}}$ \\
\hline Diabetic & (11) & $62.1 \pm 6.1$ & $51.3 \pm 6.5$ & $43.8 \pm 5.3$ & $32.4 \pm 4.5^{2}$ \\
\hline$\Rightarrow$ a $P$ & .00 & 200 & ת & & \\
\hline
\end{tabular}

and diabetic groups than in the normal and also higher in the renal glycosuric group than in the normal. These results demonstrate that the renal glycosurie group has a high-normal G.T.T. and that the oxyhyperglycemic subjects have a high fasting blood glucose level. This suggests the presence of some fundamental disturbance of carbohydrate metabolism in these subjects.

\section{Plasma Insulin}

The mean fasting plasma insulin level was slightly lower in the renal glycosuric, the borderline and the diabetic groups and higher in the oxyhyperglycemic group in comparison with that of the normal group, although the differences were not significant (Table 2). In the diabetic group, it was significantly lower than the normal at $30 \mathrm{~min}$ and higher at 90 and $120 \mathrm{~min}$. The mean $120 \mathrm{~min}$ figure of the borderline group was also higher than the normal. In the oxyhyperglycemic group, the mean $60 \mathrm{~min}$ figure was distinctly higher than the normal. There was no significant difference in the plasma insulin between the normal and the renal glycosuric group. the asymptomatic or subclinical state persists for a certain period of time. This asymptomatic state would exist even in juvenile diabetes before the classical symptoms appear. Part of this state corresponds with so-called chemical (latent) diabetes. The existence of adult-onset type diabetes among the young population has been reported by Fajans and his co-workers [15]. However, little is known about the preceding stage of chemical diabetes. It is natural to assume that the state showing a slight deviation in carbohydrate metabolism, assessed by G.T.T. as borderline, is a preexisting stage of chemical diabetes, although it has other possibilitios.

The present result obtained in a young population shows that the delay of the insulin response tends to be more remarkable and the response becomes higher and more protracted with increasing abnormality of the G.T.T. This finding is consistent with previous observations on the offspring of connubial diabetics $[16,17]$ and these results suggest that a delay and a protraction of the insulin response are characteristic of the early phase of diabetes. The insulin response is most remarkable in mild or chemical diabetes and this aug- 
mentation would presumably persist until the aggravation of the diabetic state, when the response changes to "low". Thus the plasma insulin response may change with the progression of the diabetic state as follows: normal or low at the initial or normal G.T.T. stage, delayed and high at the borderline stage, sluggish and highest at the chemical or mild diabetic stage and delayed and low at the overt-diabetio stage.

Lawrence [9] coined the name "oxybyperglycemia" and evaluated this state as innocent. However, our follow-up study showed that the subjects with this type of curve not infrequently became diabetic within a few years $[10,12]$. The present study revealed that the subjects with this blood sugar curve had a high. fasting blood glucose and the peak of their plasma insulin response was at $60 \mathrm{~min}$ in spite of the blood glucose peak being at $30 \mathrm{~min}$. This also shows a delay of the insulin response. The plasma F.F.A. response curve is also different from that of the normal. These findings are similar to those of McKiddie and her oo-workers [18] and seem to indicate that the oxybyperglycemic state is not innocent, but rather is one of the preceding stages or "Uebergangsperiode" (change and passage stage) of diabetes.

In this study the renal glycosuric subjects had a high-normal G.T.T. This is presumably because subjects with a very low renal threshold for glucose are rare. As our subjects had a normal insulin and F.F.A. response, this state seems to have no pathological meaning except a relatively lower renal threshold.

However, the nondiabetic blood relatives of diabetic patients not infrequently have a lower renal threshold [16]. A further follow-up study will be necessary to answer the question whether the renal glycosuria of Lawrence's definition is truely innocent.

\section{Referenees}

1. Colwell, J.A., Lein, A. : Diminished insulin response to hyperglycemia in prediabetes and diabetes. Diabetes $16,560-565(1967)$.

2. Hales, C.N., Greenwood, F.C., Mitchell, F.L., Strauss, W.T. : Blood-glucose, plasma-insulin and growth hormone concentrations of individuals with minor abnormalities of glucose tolerance. Diabetologia 4,73$82(1968)$.

3. Ricketts, H.T., Cherry, R.A., Kirsteins, L.: Biochemical studies of "prediabetes". Diabetes 15, 880 $888(1966)$.
4. Paulsen, E.P., Richenderfer, L., Ginsberg-Fellner, F. : Plasma glucose, free fatty acids, and immunoreactive insulin in sixty-six obese children. Diabetes 17, 261269 (1968).

5. Chlouverakis, C., Jarrett, R.J., Keen, H.: Glucose tolerance, age and circulating insulin. Lancet $1967 \mathrm{I}$, $806-809$.

6. Jackson, W.P.U., van Mieghem, W., Keller, P.: Insulin excess as the initial lesion in diabetes. Lancet $1972 \mathrm{I}, 1040-1044$.

7. Morgan, C.R., Lazarow, A.: Immunoassay of insulin using a two-antibody system. Proc. Soc. exp. Biol. $110,29-32(1962)$.

8. Itaya, K., Ui, M.: Colorimetric determination of free fatty acids in biological fluids. J. Lipid Res. 6, 16-20 (1965).

9. Lawrence, R.D. : Symptomless glycosurias: differentiation by sugar tolerance tests. Med. Clin. N. Amer. 31, $289-297$ (1947).

10. Goto, Y. Mild diabetes and borderline cases. J. Jap. Diabet. Soc. 7, 75-82, (1964).

11. Toyota, T., Goto, Y.: Glucose tolerance test performed in the afternoon. Tohoku J. exp. Med. 99, 309-313 (1969).

12. Toyota, T., Mizuhara, F.: Follow up observation of the cases with borderline glucose tolerance test. J. Jap. Diabet. Soc. 10, 234-237 (1967).

13. Goto, Y., Anzai, M., Toyota, T., Ishitoya, Y., Obazama, H., Kawahara, S.: Interpretation of glucose tolerance test. Differences in analytical methods, capillary-venous difference and glucose doses $(50 \mathrm{~g}$, $100 \mathrm{~g}$ ). Jap. J. clin. Path. 14, 258-261 (1966).

14. Goto, Y., Ito, I., Seino, K.: Peripheral utilization of glucose in diabetic patients. Tohoku J. exp. Med. 69, $113-122(1959)$.

15. Fajans, S.S., Conn, J.W.: Prediabetes, subclinical diabetes and latent clinical diabetes: Interpretation, diagnosis and treatment. In: "On the Nature and Treatment of Diabetes" (Leibel, B., Wrenshall, G. eds.), Ser. 84, pp. 641-656. New York: Excerpta med. Found. 1965.

16. Goto, Y., Toyota, T., Takaku, I., Sato, X., Trie, M.: Biochemical and functional abnormalities in prediabetic subjects. In: "Early Diabetes" (Camerini, R. and Cole, H.S., eds.), pp. 305-313. Now York: Academic Press 1970.

17. Goto, Y., Toyota, T., Maruhama, Y., Fukuhara, N., Sato, S., Chiba, M., Sato, Y.: Abnormalities in prediabetes. In: "Diabetes" (Rodriguez, R.R. and Vallance-Owen, J., eds.), pp. 240-247. Amsterdam: Excerpta med. Found. 1971.

18. MeKiddie, M.T., Scott, R.T.A., Buchanan, K.D.: Plasma insulin studies in patients with lag curves. Diabetologia 6, $420-424$ (1970).

Prof. Y. Goto

Third Department of Intemal Medicine Hirosaki University, School of Medicine Hirosaki

Japan 